\title{
A Static Control Algorithm for Adaptive Beam String Structures Based on Minimal Displacement
}

\author{
Yanbin Shen, Huaqiang Cheng, Pengcheng Yang, and Yaozhi Luo \\ College of Civil Engineering and Architecture, Zhejiang University, Hangzhou 310058, China \\ Correspondence should be addressed to Yaozhi Luo; mstcad@163.com
}

Received 1 August 2013; Revised 6 October 2013; Accepted 15 October 2013

Academic Editor: Hong-Nan Li

Copyright (C) 2013 Yanbin Shen et al. This is an open access article distributed under the Creative Commons Attribution License, which permits unrestricted use, distribution, and reproduction in any medium, provided the original work is properly cited.

\begin{abstract}
The beam string structure (BSS) is a type of prestressed structure and has been widely used in large span structures nowadays. The adaptive BSS is a typical smart structure that can optimize the working status itself by controlling the length of active struts via certain control device. The control device commonly consists of actuators in all struts and sensors on the beam. The key point of the control process is to determine the length adjustment values of actuators according to the data obtained by preinstalled sensors. In this paper, a static control algorithm for adaptive BSS has been presented for the adjustment solution. To begin with, an optimization model of adaptive BSS with multiple active struts is established, which uses a sensitivity analysis method. Next, a linear displacement control process is presented, and the adjustment values of struts are calculated by a simulated annealing algorithm. A nonlinear iteration procedure is used afterwards to calibrate the results of linear calculation. Finally, an example of adaptive BSS under different external loads is carried out to verify the feasibility and accuracy of the algorithm. And the results also show that the adaptive BSS has much better adaptivity and capability than the noncontrolled BSS.
\end{abstract}

\section{Introduction}

The beam string structure (BSS) is a type of prestressed system initially presented by Saitoh in the early 1980s $[1,2]$. It has good mechanical behavior and now has been widely used in large span structures such as airport, exhibition hall, and gym. Three most typical cases that are frequently cited in China are Shanghai Pudong International Airport Terminal, Guangzhou International Convention and Exhibition Center, and the Main Stadium of Harbin International Convention and Exhibition Center. Their span reaches $82.6 \mathrm{~m}, 126.6 \mathrm{~m}$, and $128.5 \mathrm{~m}$, respectively. The BSS commonly consists of three parts, namely, the upper beam (or a truss), the lower cable, and the vertical link strut, as shown in Figure 1. The prestress in the cable balances the horizontal thrust on the support and decreases the bending moment value on the upper beam, which greatly improves the structural stiffness and capability of the BSS. Despite its relatively light internal force, the vertical link strut still plays an important role in the entire system. Tiny changes on the length of struts will cause wide force redistribution in the entire BSS. Therefore, if the vertical link strut is converted into a kind of adjustable component, the traditional BSS would become a new kind of smart structure with self-adjustment ability and better mechanical behavior.

In recent years, smart structures have become a hot spot of research, which represents the future direction of structure development. A smart civil structure is a civil structure (e.g., buildings, bridges, dams, etc.) that can monitor and react to environmental conditions and the structure's own conditions, in a predesigned and beneficial manner [3]. Currently, in civil engineering, most research works on smart structures focus on vibration control and have made tremendous achievement. Various types of techniques and devices such as magnetorheological (MR) damper, shape memory alloy (SMA) actuator, hybrid active mass damper (AMD), and piezoceramic actuator, concentrically braced frames (CBF) are applied to vibration control [4-12]. Meanwhile, a few studies have paid attention to the smart structure based on the control of static characteristics such as deformation and internal force. Some typical cases involve the applications of smart prestress, smart strut, and smart beam $[13,14]$.

This paper illustrates a typical kind of smart structure based on static characteristics control, namely, the adaptive 


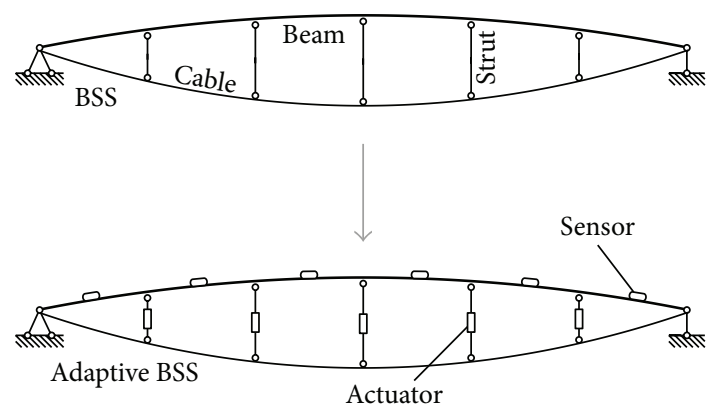

FIGURE 1: Diagram of an adaptive BSS.

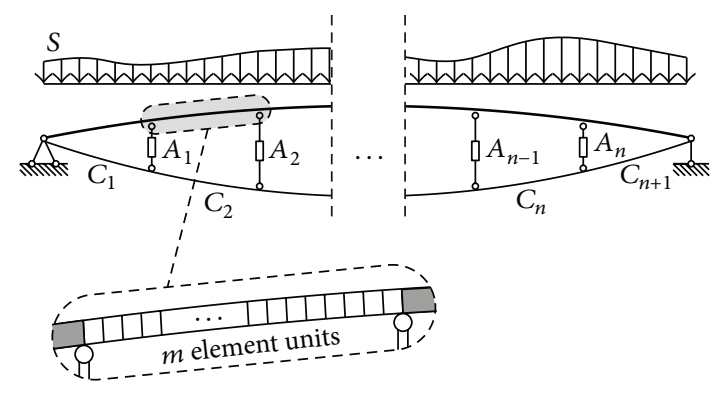

FIgUre 2: Model of an adaptive BSS.
BSS. The adaptive BSS can optimize the working status itself by controlling the length of one or several adjustable link struts according to the changes of external loads, as shown in Figure 1. The control device commonly consists of actuators in each strut and sensors on the beam. Following a typical smart structure style, the working principle is as follows. Due to the excitation of external loads, the static characteristics of the structure have made changes. The sensors placed on the structure monitor that change and transfer data to the controller. Via analysis and calculation, an adjustment strategy is generated by the controller and sent to actuators. The actuators then execute the adjustment strategy, and a complete control process ends. The key point of the control process is to determine the length adjustment values of actuators according to the displacement values obtained by sensors.

The adaptive BSS is a novel smart structure, so there are rarely systemic research works to be referenced. Some similar researches on smart beams have been reported, but those beams cannot be considered as a true BSS system and usually contain one or two struts. Basically, the static control of those kinds of smart beams includes internal force control and displacement control. Noack et al. studied the control strategy of a smart beam with one active strut under moving loads, taking the displacement as the control objective [13]. Sobek and Teuffel carried on similar work and updated the system to beams with two active struts [14]. For the smart beam with one or two active struts, heuristic selection and exhaustive method could meet the requirement of static control analysis, while for a typical adaptive BSS with a set of struts, the entire search space becomes too large and the brute methods can no longer satisfy the requirement. For large solution spaces searching problems, stochastic search techniques such as genetic algorithm (GA) and simulated annealing (SA) algorithm are usually applied. On the other hand, all works mentioned above assume that the smart prestressed system works in linearity; therefore, the linear static control method is employed. However, the BSS system usually contains a set of struts and cables which make the structure flexible to a certain degree. For a flexible structure with large displacement behavior, nonlinear method is commonly incorporated into control algorithm for better accuracy. Similar nonlinear static control method had been used in cable-strut structures in the past [15]. Although the static control optimization model for cable-strut structures is not suitable for the adaptive BSS, its nonlinear static control method could still be a good reference.

In this paper, a static control algorithm for adaptive BSS has been presented for the adjustment solution. It is based on nonlinear finite element method and SA algorithm. The paper is organized as follows. Section 2 establishes an optimization model of adaptive BSS with multiple active struts, and a sensitivity analysis method is applied. Section 3 presents a linear displacement control process mainly by means of an SA algorithm and then proposes a nonlinear iteration to calibrate the result of the linear calculation. Section 4 carries out an example of a three-strut adaptive BSS under different external loads and conducts the comparisons between results from noncontrolled BSS and adaptive BSS. Finally, a summary of the research work is given in Section 5.

\section{The Static Control Model Based on Minimal Displacement}

The mechanical model of adaptive BSS with multiple active struts is established for static control analysis at first, and a sensitivity analysis method is used to evaluate the influence of each of the multiple adjustable struts. The sensitivity analysis method was proposed early in 1980s by SobieszczanskiSobieski et al. to study the sensitivity of optimum solution of problem parameters. The basic principle of sensitivity analysis is to get the derivative of the optimum solution to multiple variables and then obtain the optimum solution and the corresponding variables via calculating the weight factors of different variables [16]. Besides, a working status factor of the BSS system based on displacement is defined as the control objective.

2.1. Mechanical Modeling of Adaptive BSS. The simplified mechanical model of a typical adaptive BSS with multiple active struts is shown in Figure 2. The upper beam is subdivided into plenty of small beam element units for more accuracy. Each active strut is considered as a single link element, and the cable segment between two joints is treated as a single cable element unit. Some assumptions are given when performing static control analysis: (1) the material nonlinearity of the adaptive BSS is not considered; (2) the fixed hinge bearing is on the left end of the beam and the sliding hinge bearing is on the right; (3) the weight of the structure is converted into equivalent dead loads, and all external loads 
are applied on the beam only; and (4) the joint connecting the cable and the strut is a hinge, and the cable between two joints is considered as a straight line with tension only, ignoring the effect of the cable sag.

The BSS is assumed to adopt linear behavior, and according to superposition principle, the internal force and displacement value of the structure after adjustment are

$$
\begin{aligned}
& \mathbf{F}_{C}=\mathbf{F}_{0}+\Delta \mathbf{F}, \\
& \mathbf{d}_{C}=\mathbf{d}_{0}+\Delta \mathbf{d},
\end{aligned}
$$

where $\mathbf{F}_{0}$ and $\mathbf{d}_{0}$ represent the internal force and displacement value of the structure before adjustment, respectively. After an arbitrary adjustment, the structure has new internal force of $\mathbf{F}_{C}$ and displacement of $\mathbf{d}_{C} \cdot \Delta \mathbf{F}$ and $\Delta \mathbf{d}$ are the increments of the internal force and displacement, respectively, which are given by

$$
\begin{aligned}
\Delta \mathbf{F} & =\mathbf{S}_{A, F} \mathbf{e}_{A}, \\
\Delta \mathbf{d} & =\mathbf{S}_{A, D} \mathbf{e}_{A},
\end{aligned}
$$

where $\mathbf{S}_{A, F}$ and $\mathbf{S}_{A, D}$ are the sensitivity matrix of internal force and displacement, respectively. $\mathbf{e}_{A}$ denotes the length adjustment values of active struts. For a specific BSS with elements amounted to $N_{e}$, nodes amounted to $N_{n}$, and adjustable struts amounted to $N_{a}$, (2) can be expressed as

$$
\begin{gathered}
{\left[\begin{array}{c}
\Delta \mathbf{F}_{1} \\
\Delta \mathbf{F}_{2} \\
\cdots \cdots \\
\Delta \mathbf{F}_{N_{e}}
\end{array}\right]=\left[\begin{array}{cccc}
\Delta \mathbf{F}_{1}^{1} & \Delta \mathbf{F}_{1}^{2} & \cdots \cdots & \Delta \mathbf{F}_{1}^{N_{a}} \\
\Delta \mathbf{F}_{2}^{1} & \Delta \mathbf{F}_{2}^{2} & \cdots \cdots & \Delta \mathbf{F}_{2}^{N_{a}} \\
\cdots \cdots & \cdots \cdots & \Delta \mathbf{F}_{i}^{j} & \cdots \cdots \\
\Delta \mathbf{F}_{N_{e}}^{1} & \Delta \mathbf{F}_{N_{e}}^{2} & \cdots \cdots & \Delta \mathbf{F}_{N_{e}}^{N_{a}}
\end{array}\right]\left[\begin{array}{c}
e_{A 1} \\
e_{A 2} \\
\cdots \cdots \\
e_{A N_{a}}
\end{array}\right],} \\
{\left[\begin{array}{c}
\Delta \mathbf{d}_{1} \\
\Delta \mathbf{d}_{2} \\
\cdots \cdots \\
\Delta \mathbf{d}_{N_{n}}
\end{array}\right]=\left[\begin{array}{cccc}
\Delta \mathbf{d}_{1}^{1} & \Delta \mathbf{d}_{1}^{2} & \cdots \cdots & \Delta \mathbf{d}_{1}^{N_{a}} \\
\Delta \mathbf{d}_{2}^{1} & \Delta \mathbf{d}_{2}^{2} & \cdots \cdots & \Delta \mathbf{d}_{2}^{N_{a}} \\
\cdots & \cdots & \Delta \mathbf{d}_{i}^{j} & \cdots \\
\Delta \mathbf{d}_{N_{n}}^{1} & \Delta \mathbf{d}_{N_{n}}^{2} & \cdots \cdots & \Delta \mathbf{d}_{N_{n}}^{N_{a}}
\end{array}\right]\left[\begin{array}{c}
e_{A 1} \\
e_{A 2} \\
\cdots \cdots \\
e_{A N_{a}}
\end{array}\right],}
\end{gathered}
$$

where $\Delta \mathbf{d}_{i}^{j}$ denotes the displacement increment of node $j$ when the adjustable strut $i$ changes a unit value, and it is described as $\left[\Delta \mathbf{d}_{i}^{j, x}, \Delta \mathbf{d}_{i}^{j, y}, \Delta \mathbf{d}_{i}^{j, z}\right]^{T} . \Delta \mathbf{F}_{i}^{j}$ indicates the internal force increment of element $j$ when the adjustable strut $i$ changes a unit value, and it is described as $\left[\Delta N_{i}^{j, L}, \Delta S_{i}^{j, L}\right.$, $\left.\Delta M_{i}^{j, L}, \Delta N_{i}^{j, R}, \Delta S_{i}^{j, R}, \Delta M_{i}^{j, R}\right]^{T}$ for beam element and $\left[\Delta N_{i}^{j, L}\right.$, $\left.\Delta N_{i}^{j, R}\right]^{T}$ for cable and link elements.

2.2. The Minimal Displacement Control Objective. The BSS is a self-balancing system with a set of link struts connecting the beam and the cable. The beam withstands external loads directly and bears bending moment and pressure. The prestress applied in the cable largely decreases the maximum values of internal force and displacement of the beam. Technically, the function of the prestressed cable and link struts is to improve the capability of the beam, and the mechanical behavior of the beam reflects the performance of the entire BSS system. In this paper, a displacement state factor $f_{D j}$ of the beam is specified with (5) to identify the performance of the system:

$$
f_{D j}= \begin{cases}\frac{d_{B j}}{d_{B}^{U}}, & d_{B j} \geq 0, \\ \frac{d_{B j}}{d_{B}^{L}}, & d_{B j}<0,\end{cases}
$$

in which $d_{B}^{U}$ and $d_{B}^{L}$ refer to the upper bound and lower bound of the adjustable displacement range of node $j$ on the beam, respectively. Normally the length of $1 / 250$ span of the structure is considered as the allowable value according to design code. $d_{B j}$ is the displacement value of node $j$.

A working status factor $\beta_{D}$ of the BSS system based on displacement is given by

$$
\beta_{D}=\max \left(f_{D j}\right), \quad j=1,2, \ldots, n+1,
$$

where $n$ is the amount of subdivisions of the beam.

The optimum design for a traditional BSS is to search the structural shape, component cross-section size, and cable prestress to satisfy the requirement of $\beta_{D} \leq 1$ under the most unfavorable load. For an adaptive BSS, the basic principle of displacement control is to improve the internal force distribution and decrease the maximal value of displacement via adjusting the length of the active struts. When $\beta_{D}$ reaches the minimum, the working status of the BSS is probably the best.

In addition, during the control process, some other conditions such as the structural material strength and the adjustment range of the active struts should be satisfied at the same time. All constraint conditions are detailed as

$$
\begin{gathered}
d_{B}^{L} \leq d_{B j} \leq d_{B}^{U}, \\
\sigma_{B}^{C} \leq \sigma_{B j} \leq \sigma_{B}^{T}, \\
\sigma_{A}^{C} \leq \sigma_{A j} \leq 0, \\
N_{C}^{L} \leq N_{C j} \leq N_{C}^{T}, \\
e_{A}^{L} \leq e_{A j} \leq e_{A}^{U},
\end{gathered}
$$

where $\sigma_{B}^{C}$ and $\sigma_{B}^{T}$ are the allowable compressive and tensional stress values of the beam, respectively. $\sigma_{A}^{C}$ is the allowable compressive stress value of the active strut. $N_{C}^{T}$ denotes the allowable tensional force value of cables, and $N_{C}^{L}$ is the lower bound of tensional force range that usually equals $5 \%$ of $N_{C}^{T}$. $e_{A}^{L}$ and $e_{A}^{U}$ stand for the lower bound and upper bound of the adjustment length range of the active strut. $d_{B j}, \sigma_{B j}, \sigma_{A j}, N_{C j}$, and $e_{A j}$ denote the displacement value of node $j$ of the beam, the stress value of element unit $j$ of the beam, the stress value of active struts $j$, the tensional force of cable $j$, and the length 
adjustment value of active strut $j$, respectively. Detailed stress expressions of different structural components are specified as

$$
\begin{gathered}
\sigma_{B j}=\frac{N_{B j, L}}{A_{B j}} \pm \max \left(\left|\frac{M_{B j, L}}{W_{B j}}\right|,\left|\frac{M_{B j, R}}{W_{B j}}\right|\right), \\
\sigma_{A j}=\frac{N_{A j, L}}{A_{A j}},
\end{gathered}
$$

where $N_{B j, L}, M_{B j, L}$, and $M_{B j, R}$ are the axial force, moment on left end and moment on right end of the unit $j$ of the beam, respectively. $A_{B j}$ and $W_{B j}$ are the cross-section area and inertia modulus of the unit $j$ of the beam, respectively. $N_{A j, L}$ and $A_{A j}$ are the axial force and cross-section area of the active strut $j$.

In summary, the static control analysis based on minimal displacement to adaptive BSS is treated as an optimization problem, with $\beta_{D}$ as the cost function and (7) to (11) as constraints, which is indicated in

$$
\begin{array}{ll}
\text { solve } & e_{A} \\
\text { make } & \beta_{D}\left(e_{A}\right) \longrightarrow \min \\
\text { s.t. } & (7) \text { to }(11) .
\end{array}
$$

\section{The Static Control Algorithm}

3.1. Linear Displacement Control Process Using SA. Linear displacement control (LDC) is a basis of nonlinear displacement control (NDC). In this paper, SA algorithm is employed to search an optimal adjustment solution. It is a stochastic search method that has been successfully applied to a variety of problems in optimization research. In its application to this paper, the entire calculation process starts with randomly generating a set of $e_{A}$ that satisfy (11) and evaluating the working status factor $\beta_{D}$ and all static results of this selection. And then a new selection of $e_{A}$ is generated by a random alteration within a neighborhood of last selection. The $\beta_{D}$ of the new selection is calculated and compared with the minimum $\beta_{D}$ of all the previous selections. If the current $\beta_{D}$ is lower than the minimum $\beta_{D}$, the new selection takes over directly. Otherwise, a Metropolis algorithm is used to determine whether the new selection of $e_{A}$ is accepted or not. And for every Mapkob length of repetitions of the above procedure, a cooling operation is performed once. It will not stop until the optimized value to the minimum $\beta_{D}$ is lower than the given criterion $\varepsilon$ or the system is cooled over. The flowchart of the entire process described above is summarized in Figure 3.

3.2. Nonlinear Displacement Control Procedures. The linear displacement control algorithm presented in the previous section is no longer suitable when considering the structural nonlinearity of the BSS system. Referring to the nonlinear finite element method and based on the LDC algorithm, the NDC algorithm is established via applying an iterative procedure analogous to the Newton-Raphson method, as shown in Figure 4. Firstly, an approximate solution has been obtained by using the LDC algorithm, as shown by $\mathrm{AB}$ in Figure 4.
And then the structural response from the linear solution is revised to its real state $C$ by nonlinear finite element method (NFEM). The above process can be repeated at any new state (e.g., C) until the structure converges to the target state.

For NDC algorithm, (1) is no longer valid and should be replaced by the iterative equations as

$$
\begin{aligned}
& \mathbf{F}_{C}^{(k)}=\mathbf{F}_{C}^{(k-1)}+\delta \mathbf{F}^{(k)}, \\
& \mathbf{d}_{C}^{(k)}=\mathbf{d}_{0}^{(k-1)}+\delta \mathbf{d}^{(k)},
\end{aligned}
$$

where $\mathbf{F}_{C}^{(k)}$ and $\mathbf{d}_{C}^{(k)}$ are the estimated solution of the internal force and displacement on $k$ step, respectively. $\mathbf{F}_{C}^{(k-1)}$ and $\mathbf{d}_{C}^{(k-1)}$ are the real state of the internal force and displacement on $k-1$ step. $\delta \mathbf{F}^{(k)}$ and $\delta \mathbf{d}^{(k)}$ are calculated according to $\delta e^{(k)}$ which is generated by LDC with $\beta_{D \text {,min }}{ }^{(k)}$ as the target. Accordingly, at each iteration step, the deviation of the working status factor from the real state is defined as

$$
\beta_{D}^{\prime(k)}=\beta_{D, \min }{ }^{(k)}-\beta_{D}{ }^{(k)}
$$

where $\beta_{D}^{\prime(k)}$ means the deviation of the working status factor on $k$ step, $\beta_{D \text {,min }}{ }^{(k)}$ is the minimal working status factor generated by LDC on $k$ step, and $\beta_{D}{ }^{(k)}$ denotes the working status factor of real state after revision by NFEM. Accordingly, the deviation of the internal force and displacement from the real state can also be expressed by $F_{C}^{\prime(k)}$ and $d_{C}^{\prime(k)}$, respectively. By introducing a Newton-Raphson iterative procedure to (14), they can converge to the optimal state of the structure finally.

The flowchart of the solution searching process of NDC algorithm is shown in Figure 5. A Matlab program has been written to implement the algorithm and has been used for the example in the next section.

\section{Example}

As shown in Figure 6, a three-strut adaptive BSS with a span of 48 meters and an inverted rise of 6 meters is considered as an example for the control algorithm verification. The straight beam (thick line) employs a square cross section steel tube, and the size of the cross section is $300 \mathrm{~mm}$ in width, $400 \mathrm{~mm}$ in height, and $20 \mathrm{~mm}$ in wall thickness. The beam is subdivided into 120 small beam element units for more accurate calculation. The three active link struts (middle thick line) are circular pipes with a diameter of $140 \mathrm{~mm}$ and a wall thickness of $6 \mathrm{~mm}$. The cable (light line) consists of 61 steel wires with a diameter of $5 \mathrm{~mm}$, and the prestress in the cable is produced by the dead load. In calculation, all constraint conditions are detailed as shown in Table 1 . The elasticity modulus of the beam and struts is $2.06 \times 10^{5} \mathrm{~N} / \mathrm{mm}^{2}$, and that of the cable is $1.95 \times 10^{5} \mathrm{~N} / \mathrm{mm}^{2}$.

For a roof structure, there are usually four types of external loads being considered, namely, the dead load, the full span live load, the half span live load, and the upward wind load. They are notated as $S_{G}, S_{\mathrm{Q} 1}, S_{\mathrm{Q} 2}$, and $S_{W}$, respectively. Assume that all loads are applied on the beam, and $S_{G}=$ $5 \mathrm{kN} / \mathrm{m}$. Three typical load cases are calculated for the next 


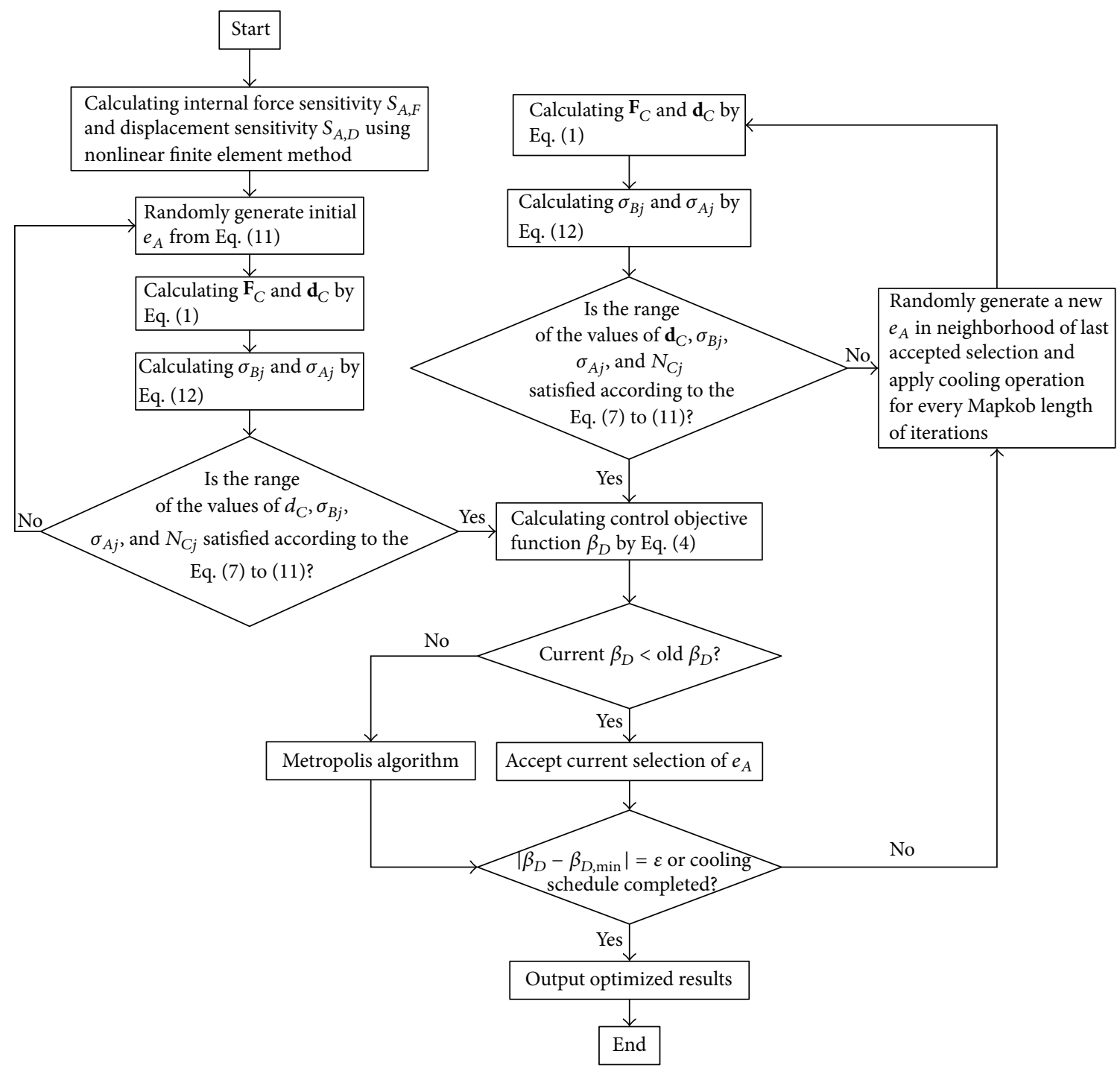

FIGURE 3: SA process for LDC solution.

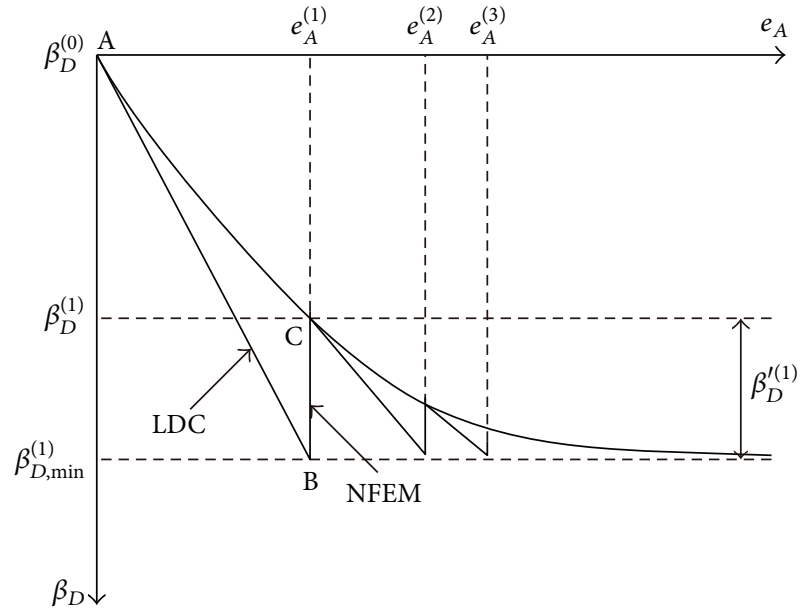

FIGURE 4: Illustration of iterations in searching for solution of NDC. discussion. Load Case $1, S_{G}+S_{\mathrm{Q} 1}$, is the most unfavorable downward load case with uniform distribution. Load Case 2, $S_{G}+S_{Q 2}$, is the most unfavorable downward load case with unsymmetrical distribution. Load Case $3, S_{G}+S_{W}$, is the most unfavorable upward load case with uniform distribution. In this section, the ultimate loads of $S_{\mathrm{Q} 1}, S_{\mathrm{Q} 2}$, and $S_{W}$ under the three load cases above are calculated in the case of noncontrolled and controlled structure, respectively. And all the static state results of noncontrol, LDC, and NDC are discussed in details to validate the algorithm and prove the capability of the adaptive system.

4.1. Load Case 1: $S_{\mathrm{G}}+S_{\mathrm{Q} 1}$. The ultimate load of $S_{\mathrm{Q} 1}$ for noncontrolled BSS is calculated as $S_{\mathrm{Q} 1}=5.2 \mathrm{kN} / \mathrm{m}$, which is subject to all constraint conditions in Table 1 . With the value of $S_{\mathrm{Q} 1}$ obtained, calculation under load Case $1, S_{G}(5 \mathrm{kN} / \mathrm{m})+$ $S_{\mathrm{Q} 1}(5.2 \mathrm{kN} / \mathrm{m})$, for noncontrol, LDC, and NDC is then 
TABLE 1: Constraint conditions for calculation.

\begin{tabular}{lccccccc}
\hline $\begin{array}{c}\text { Allowable displacement } \\
\text { of the beam }(\mathrm{mm})\end{array}$ & $\begin{array}{c}\text { Allowable stress of } \\
\text { struts }\left(\mathrm{N} / \mathrm{mm}^{2}\right)\end{array}$ & $\begin{array}{c}\text { Allowable adjustment } \\
\text { of struts }(\mathrm{mm})\end{array}$ & \multicolumn{2}{c}{$\begin{array}{c}\text { Allowable tension of } \\
\text { cables }(\mathrm{kN})\end{array}$} & \multicolumn{2}{c}{$\begin{array}{c}\text { Allowable stress of the } \\
\text { beam }\left(\mathrm{N} / \mathrm{mm}^{2}\right)\end{array}$} \\
\hline$d_{B}^{L}$ & $d_{B}^{U}$ & $\sigma_{A}^{C}$ & $e_{A}^{L}$ & $e_{A}^{U}$ & $N_{C}^{L}$ & $N_{C}^{T}$ & $\sigma_{B}^{C}$ \\
-192 & 192 & -215 & -400 & 400 & 98 & 1880 & $\sigma_{B}^{T}$ \\
\hline
\end{tabular}

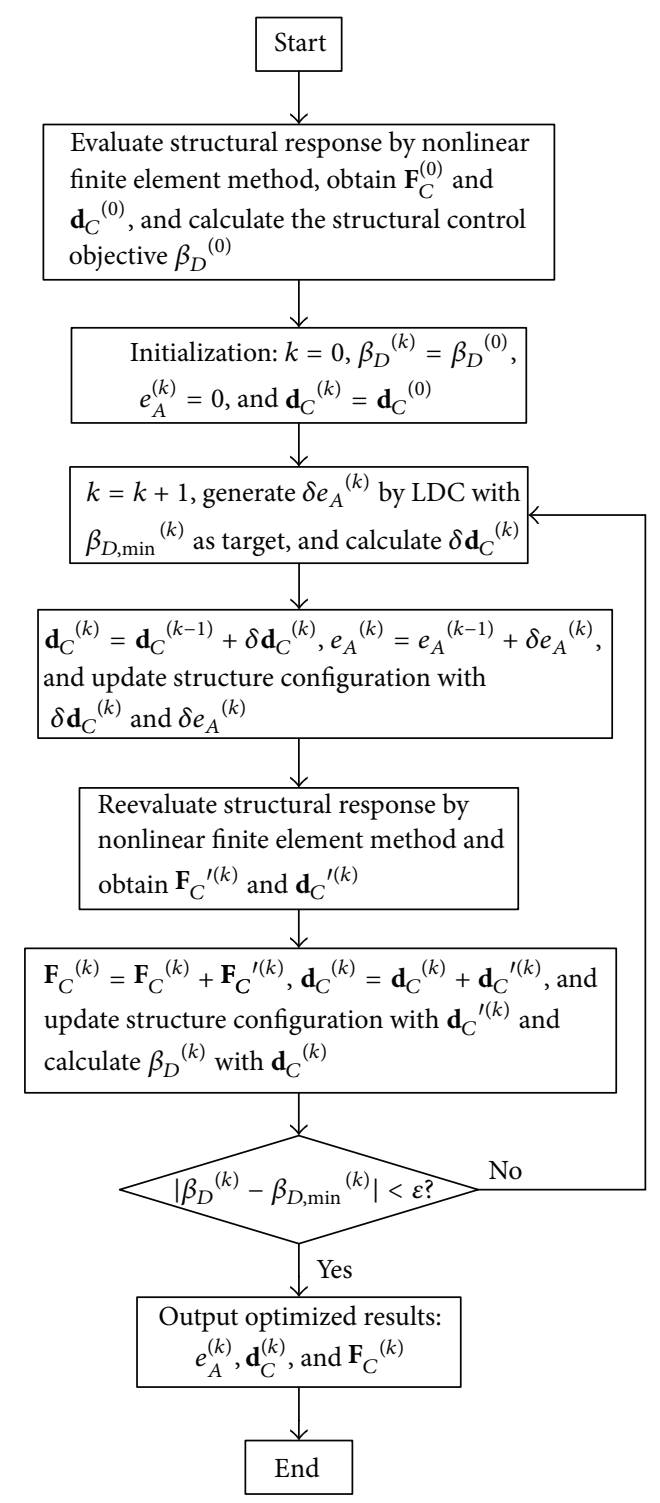

FIgURE 5: Procedures of solution searching for NDC.

followed, and all the static state results are shown in Table 2. It turns out that the ultimate load of $S_{\mathrm{Q} 1}$ is literally subject to the allowable displacement of the beam; that is, $\beta_{D}$ is close to 1 . And the adjustment effect of NDC is slightly better than LDC according to $\beta_{D}$.

For the main bearing component, namely, the beam, the displacement and moment state directly reflect its working state, as shown in Figures 7 and 8, where the abscissa axis represents the location on the beam. After control, the displacement state improvement is obvious to see and the

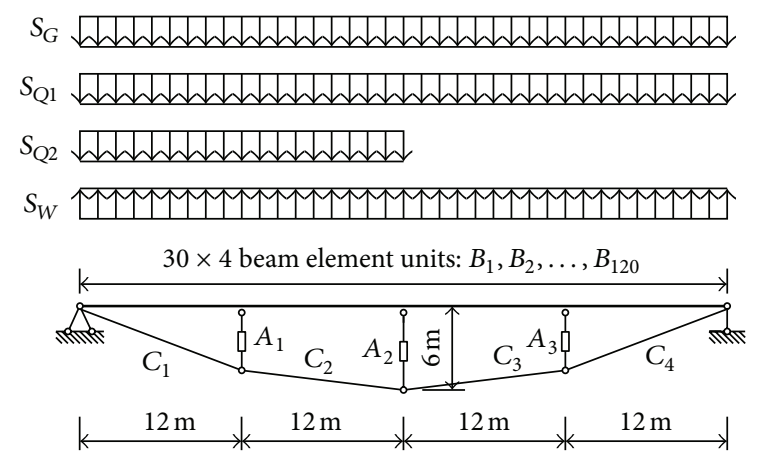

Figure 6: A three-strut adaptive BSS.

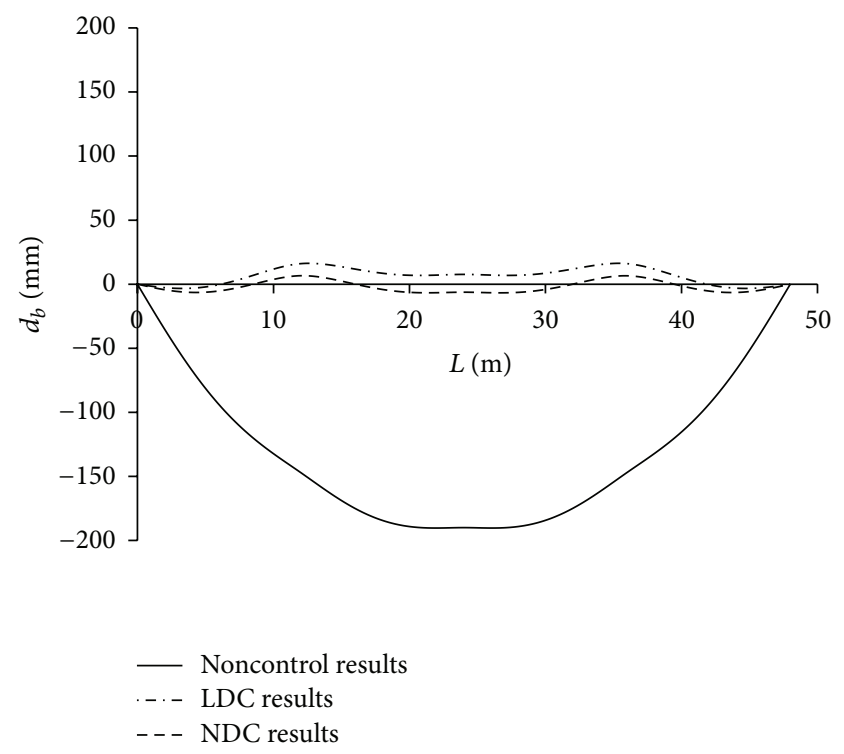

Figure 7: Displacement state of the beam under load Case 1.

moment values become well distributed around the abscissa axis.

For further comparison, the ultimate load of $S_{\mathrm{Q} 1}$ for the adaptive BSS is calculated as $S_{\mathrm{Q} 1}=28.0 \mathrm{kN} / \mathrm{m}$, which is also subject to all constraint conditions. That is to say, after the NDC, the ultimate load level of the structure has increased up to 438 percent. With calculation done under load Case 1: $S_{G}$ $(5 \mathrm{kN} / \mathrm{m})+S_{\mathrm{Q} 1}(28.0 \mathrm{kN} / \mathrm{m})$ and all constraint conditions for the noncontrolled structure released, the static state results of noncontrol and NDC are shown in Table 3. It is clear that the ultimate load of $S_{\mathrm{Q} 1}$ is subject to the allowable stress of the beam; that is, $\left|\sigma_{B}\right|_{\max }$ is close to $215 \mathrm{~N} / \mathrm{mm}^{2}$; meanwhile, the adjustments of strut 1 and strut 3 all reach the upper bound. 
TABLE 2: Static state results under load Case 1 with $S_{\mathrm{Q}}=5.2 \mathrm{kN} / \mathrm{m}$.

\begin{tabular}{lccccccccccc}
\hline & $\begin{array}{c}\text { Working } \\
\text { status factors }\end{array}$ & \multicolumn{2}{c}{$\begin{array}{c}\text { Compressive stress } \\
\text { values of struts }\left(\mathrm{N} / \mathrm{mm}^{2}\right)\end{array}$} & $\begin{array}{c}\text { Adjustment values of } \\
\text { struts }(\mathrm{mm})\end{array}$ & $\begin{array}{c}\text { Minimal and maximum } \\
\text { tension values of cables } \\
(\mathrm{kN})\end{array}$ & $\begin{array}{c}\text { Maximum stress } \\
\text { values of the beam } \\
\left(\mathrm{N} / \mathrm{mm}^{2}\right)\end{array}$ \\
\hline Notations & $\beta_{D}$ & $\sigma_{A 1}$ & $\sigma_{A 2}$ & $\sigma_{A 3}$ & $e_{A 1}$ & $e_{A 2}$ & $e_{A 3}$ & $N_{C, \min }$ & $N_{C, \max }$ & $\left|\sigma_{B}\right|_{\max }$ \\
Noncontrol results & $0.992 \uparrow$ & -51.23 & -50.76 & -51.23 & 0.00 & 0.00 & 0.00 & 503.60 & 535.10 & 77.15 & 540.58 \\
LDC results & 0.085 & -59.18 & -39.71 & -59.18 & 261.60 & -47.70 & 261.70 & 506.77 & 87.16 & 540.63 & 85.90 \\
NDC results & 0.035 & -59.31 & -39.52 & -59.31 & 253.80 & -66.00 & 253.50 & 506.84 & 54 \\
\hline
\end{tabular}

TABLE 3: Static state results under load Case 1 with $S_{\mathrm{Q} 1}=28.0 \mathrm{kN} / \mathrm{m}$.

\begin{tabular}{lcccccccccc}
\hline & $\begin{array}{c}\text { Working } \\
\text { status factor }\end{array}$ & \multicolumn{2}{c}{$\begin{array}{c}\text { Compressive stress of } \\
\text { struts }\left(\mathrm{N} / \mathrm{mm}^{2}\right)\end{array}$} & $\begin{array}{c}\text { Adjustment value of } \\
\text { struts }(\mathrm{mm})\end{array}$ & $\begin{array}{c}\text { Minimal and maximum } \\
\text { tension of cables }(\mathrm{kN})\end{array}$ & $\begin{array}{c}\text { Maximum stress of } \\
\text { beam }\left(\mathrm{N} / \mathrm{mm}^{2}\right)\end{array}$ \\
\hline Notations & $\beta_{D}$ & $\sigma_{A 1}$ & $\sigma_{A 2}$ & $\sigma_{A 3}$ & $e_{A 1}$ & $e_{A 2}$ & $e_{A 3}$ & $N_{C, \min }$ & $N_{C, \max }$ & $\left|\sigma_{B}\right|_{\max }$ \\
Noncontrol results & $\mathbf{4 . 2 4 7}$ & -180.25 & -174.15 & -180.25 & 0.00 & 0.00 & 0.00 & 1637.07 & 1750.32 & $\mathbf{4 8 6 . 8 9}$ \\
NDC results & 0.516 & -178.55 & -151.45 & -178.55 & $399.90 \uparrow$ & 385.70 & $399.90 \uparrow$ & 1557.37 & 1666.44 & $214.99 \uparrow$ \\
\hline
\end{tabular}
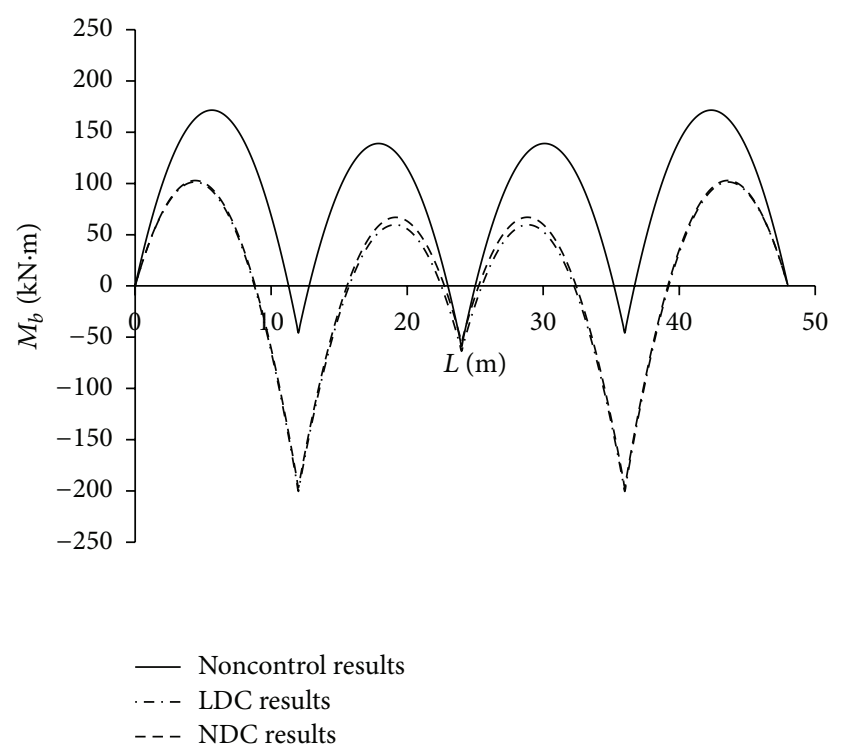

FIGURE 8: Moment state of the beam under load Case 1.

The noncontrol results show that the displacement and stress values of the beam all largely exceed the limitation.

4.2. Load Case 2: $S_{G}+S_{\mathrm{Q} 2}$. Similarly, the ultimate load of $S_{\mathrm{Q} 2}$ for noncontrolled BSS is calculated as $S_{\mathrm{Q} 2}=4.3 \mathrm{kN} / \mathrm{m}$. Table 4 shows all the static state results of noncontrol, LDC, and NDC under load Case 2: $S_{G}(5 \mathrm{kN} / \mathrm{m})+S_{\mathrm{Q} 2}(4.3 \mathrm{kN} / \mathrm{m})$. Apparently, the ultimate load of $S_{\mathrm{Q} 2}$ is still subject to the allowable displacement of the beam, and the adjustment effect of NDC is somewhat more significant than LDC. The adjustments of strut 1 and strut 3 reach the upper bound, and lower bound respectively, which indicates that wider adjustment range is required for unsymmetrically distributed loads.

The displacement and moment distributions of the beam are shown in Figures 9 and 10, respectively. After control, the displacement and moment states turn to be well distributed, and the negative influence of the unsymmetrical loads has decreased substantially.
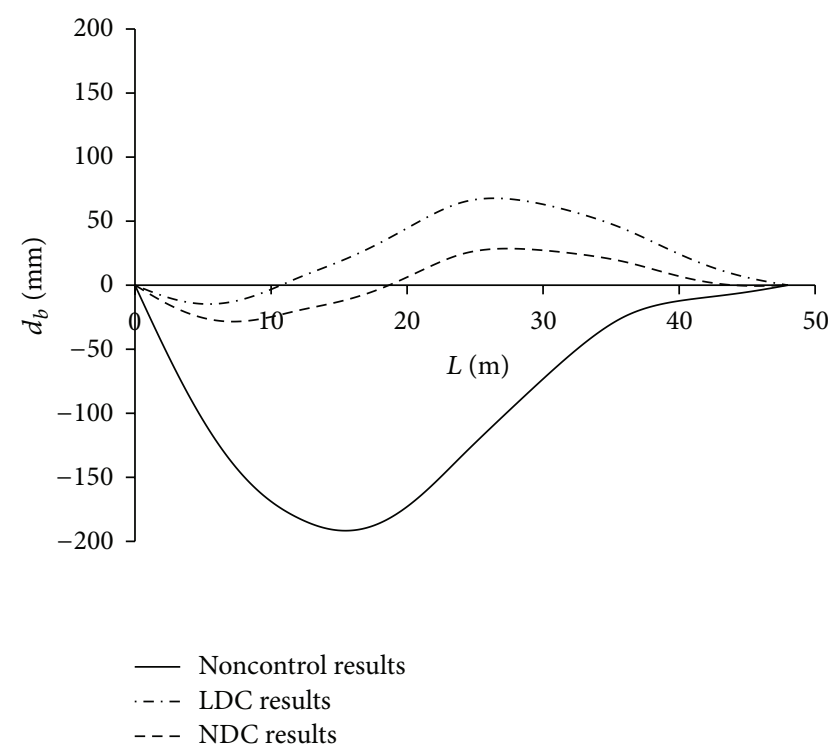

Figure 9: Displacement state of the beam under load Case 2.

For the adaptive BSS, the ultimate load of $S_{\mathrm{Q} 2}$ is calculated as $S_{\mathrm{Q}_{2}}=15.3 \mathrm{kN} / \mathrm{m}$. It increases up to 256 percent after the NDC, which may be limited by the adjustment bound of the struts. Another round of calculation is conducted under load Case 2: $S_{G}(5 \mathrm{kN} / \mathrm{m})+S_{\mathrm{Q} 2}(15.3 \mathrm{kN} / \mathrm{m})$, and all constraint conditions for the non-controlled structure are released. Results shown in Table 5 reveal that the ultimate load of $S_{\mathrm{Q}_{2}}$ is still subject to the allowable displacement of the beam; meanwhile, the adjustments of strut 1 and strut 2 have reached the upper bound. The noncontrol results show that the displacement and stress values of the beam have largely exceeded the limitation as well.

4.3. Load Case 3: $S_{G}+S_{W}$. The ultimate upward load of $S_{W}$ for noncontrolled BSS is calculated as $S_{W}=-3.0 \mathrm{kN} / \mathrm{m}$. Table 6 presents calculation results under load Case $3: S_{G}(5 \mathrm{kN} / \mathrm{m})+$ $S_{W}(-3.0 \mathrm{kN} / \mathrm{m})$. It turns out that the ultimate upward load of $S_{W}$ is subject to the allowable minimal tension of the cable. 
TABLE 4: Static state results under load Case 2 with $S_{\mathrm{Q} 2}=4.3 \mathrm{kN} / \mathrm{m}$.

\begin{tabular}{lcccccccccc}
\hline & $\begin{array}{c}\text { Working } \\
\text { status factors }\end{array}$ & \multicolumn{2}{c}{$\begin{array}{c}\text { Compressive stress } \\
\text { values of struts }\left(\mathrm{N} / \mathrm{mm}^{2}\right)\end{array}$} & $\begin{array}{c}\text { Adjustment values of } \\
\text { struts }(\mathrm{mm})\end{array}$ & $\begin{array}{c}\text { Minimal and maximum } \\
\text { tension values of cables } \\
(\mathrm{kN})\end{array}$ & $\begin{array}{c}\text { Maximum stress } \\
\text { values of the beam } \\
\left(\mathrm{N} / \mathrm{mm}^{2}\right)\end{array}$ \\
\hline Notations & $\beta_{D}$ & $\sigma_{A 1}$ & $\sigma_{A 2}$ & $\sigma_{A 3}$ & $e_{A 1}$ & $e_{A 2}$ & $e_{A 3}$ & $N_{C, \min }$ & $N_{C, \max }$ & $\left.\sigma_{B}\right|_{\max }$ \\
Noncontrol results & $0.999 \uparrow$ & -37.40 & -35.32 & -33.68 & 0.00 & 0.00 & 0.00 & 352.66 & 375.00 & 96.48 \\
LDC results & 0.353 & -41.93 & -41.99 & 21.58 & $399.90 \uparrow$ & 311.60 & $-394.10 \uparrow$ & 359.53 & 383.38 & 80.29 \\
NDC results & 0.148 & -42.87 & -40.41 & -22.53 & $399.40 \uparrow$ & 233.10 & $-398.70 \uparrow$ & 358.39 & 382.39 & 68.75 \\
\hline
\end{tabular}

TABLE 5: Static state results under load Case 2 with $S_{\mathrm{Q}_{2}}=15.3 \mathrm{kN} / \mathrm{m}$.

\begin{tabular}{lcccccccccc}
\hline & $\begin{array}{c}\text { Working } \\
\text { status factors }\end{array}$ & \multicolumn{2}{c}{$\begin{array}{c}\text { Compressive stress } \\
\text { values of struts }\left(\mathrm{N} / \mathrm{mm}^{2}\right)\end{array}$} & $\begin{array}{c}\text { Adjustment values of } \\
\text { struts }(\mathrm{mm})\end{array}$ & $\begin{array}{c}\text { Minimal and maximum } \\
\text { tension values of cables } \\
(\mathrm{kN})\end{array}$ & $\begin{array}{c}\text { Maximum stress } \\
\text { values of the beam } \\
\left(\mathrm{N} / \mathrm{mm}^{2}\right)\end{array}$ \\
\hline Notations & $\beta_{D}$ & $\sigma_{A 1}$ & $\sigma_{A 2}$ & $\sigma_{A 3}$ & $e_{A 1}$ & $e_{A 2}$ & $e_{A 3}$ & $N_{C, \min }$ & $N_{C, \max }$ & $\left.\sigma_{B}\right|_{\max }$ \\
Noncontrol results & $\mathbf{3 . 5 1 3}$ & -76.02 & -63.63 & -52.13 & 0.00 & 0.00 & 0.00 & 623.13 & 665.73 & 476.22 \\
NDC results & $0.991 \uparrow$ & -79.05 & -75.39 & -31.05 & $399.90 \uparrow$ & $399.90 \uparrow$ & -354.90 & 625.84 & 669.20 & 202.83 \\
\hline
\end{tabular}

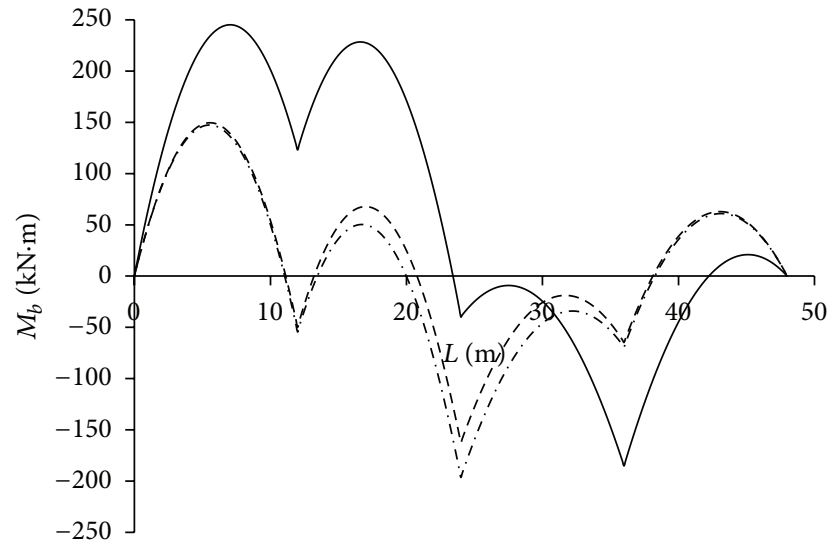

_ Noncontrol results
-.- LDC results
- - NDC results

Figure 10: Moment state of the beam under load Case 2.

All the static state results are small and close, which means the effect of adjustment is not that obvious.

As shown in Figures 11 and 12, the improvements of the displacement and moment states after control are slight.

Finally, the ultimate load of $S_{W}$ for the adaptive BSS is calculated as $S_{W}=-3.3 \mathrm{kN} / \mathrm{m}$ which increases only 10 percent. Calculation under load Case 3: $S_{G}(5 \mathrm{kN} / \mathrm{m})+S_{W}$ $(-3.3 \mathrm{kN} / \mathrm{m})$ is done with all constraint conditions for the noncontrolled structure released. The static state results of noncontrol and NDC are shown in Table 7. Obviously, the ultimate load of $S_{W}$ is still subject to the allowable minimal tension of the cable; meanwhile, the adjustments of strut 2 reach the lower bound. The noncontrol results indicate that the minimal tension value of the cable has exceeded the limitation significantly.

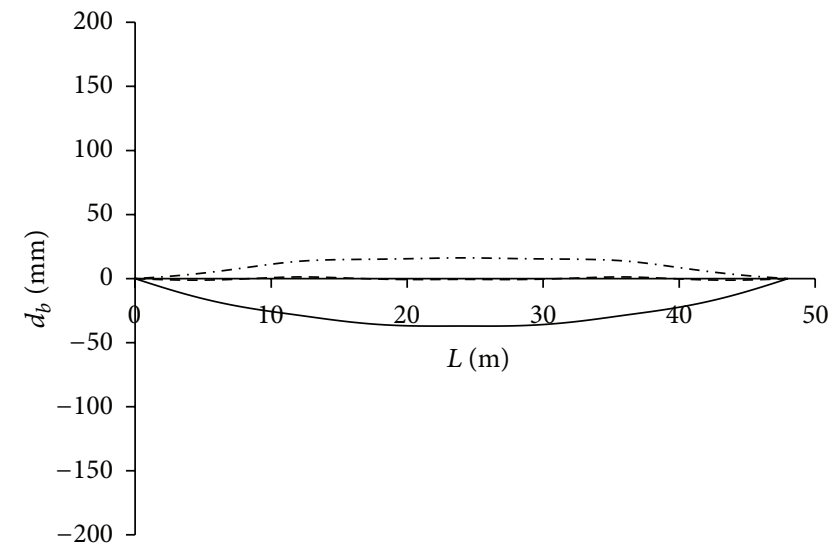

_ Noncontrol results
-.- LDC results
-.- NDC results

FIGURE 11: Displacement state of the beam under load Case 3.

\section{Conclusions}

The adaptive BSS is a typical smart structure that can optimize its own working status by controlling the length of several active struts. The core issue here is to determine the length adjustment values of the active struts according to the working status of the structure. In this paper, an optimization model of adaptive BSS with multiple active struts is established at first. It is based on a sensitivity analysis method and takes displacement as control objective. Then, on the basis of an SA algorithm, an LDC process has been proposed to calculate the adjustment. An iteration procedure consisting of the LDC process and a nonlinear iteration is constructed afterwards to achieve the displacement control of structures with nonlinear behaviour. In the final section, an example of a three-strut active BSS under different external loads has been 
TABLE 6: Static state results under load Case 3 with $S_{W}=-3.0 \mathrm{kN} / \mathrm{m}$.

\begin{tabular}{lcccccccccc}
\hline & $\begin{array}{c}\text { Working } \\
\text { status factors }\end{array}$ & \multicolumn{4}{c}{$\begin{array}{c}\text { Compressive stress } \\
\text { values of struts }\left(\mathrm{N} / \mathrm{mm}^{2}\right)\end{array}$} & $\begin{array}{c}\text { Adjustment values of } \\
\text { struts }(\mathrm{mm})\end{array}$ & $\begin{array}{c}\text { Minimal and maximum } \\
\text { tension values of cables } \\
(\mathrm{kN})\end{array}$ & $\begin{array}{c}\text { Maximum stress } \\
\text { values of the beam } \\
\left(\mathrm{N} / \mathrm{mm}^{2}\right)\end{array}$ \\
\hline Notations & $\beta_{D}$ & $\sigma_{A 1}$ & $\sigma_{A 2}$ & $\sigma_{A 3}$ & $e_{A 1}$ & $e_{A 2}$ & $e_{A 3}$ & $N_{C, \min }$ & $N_{C, \max }$ & $\left|\sigma_{B}\right|_{\max }$ \\
Noncontrol results & 0.194 & -9.74 & -9.72 & -9.74 & 0.00 & 0.00 & 0.00 & $94.56 \uparrow$ & 104.50 & 14.71 \\
LDC results & 0.084 & -11.74 & -7.83 & -11.79 & 141.20 & -191.40 & 147.90 & 103.08 & 109.73 & 19.25 \\
NDC results & 0.007 & -11.52 & -7.89 & -11.51 & 125.90 & -190.60 & 125.60 & 101.81 & 108.35 & 16.42 \\
\hline
\end{tabular}

TABLE 7: Static state results under load Case 3 with $S_{W}=-3.3 \mathrm{kN} / \mathrm{m}$.

\begin{tabular}{lcccccccccc}
\hline & $\begin{array}{c}\text { Working } \\
\text { status factors }\end{array}$ & \multicolumn{2}{c}{$\begin{array}{c}\text { Compressive stress } \\
\text { values of struts }\left(\mathrm{N} / \mathrm{mm}^{2}\right)\end{array}$} & $\begin{array}{c}\text { Adjustment values of } \\
\text { struts }(\mathrm{mm})\end{array}$ & $\begin{array}{c}\text { Minimal and maximum } \\
\text { tension values of cables } \\
(\mathrm{kN})\end{array}$ & $\begin{array}{c}\text { Maximum stress } \\
\text { values of the beam } \\
\left(\mathrm{N} / \mathrm{mm}^{2}\right)\end{array}$ \\
\hline Notations & $\beta_{D}$ & $\sigma_{A 1}$ & $\sigma_{A 2}$ & $\sigma_{A 3}$ & $e_{A 1}$ & $e_{A 2}$ & $e_{A 3}$ & $N_{C, \min }$ & $N_{C, \max }$ & $\left|\sigma_{B}\right|_{\max }$ \\
Noncontrol results & 0.164 & -8.27 & -8.26 & -8.27 & 0.00 & 0.00 & 0.00 & $\mathbf{8 3 . 7 7}$ & $\mathbf{8 8 . 8 2}$ & 12.49 \\
NDC results & 0.428 & -12.06 & -5.02 & -12.02 & 269.90 & $-399.90 \uparrow$ & 261.60 & $93.97 \uparrow$ & 100.29 & 30.85 \\
\hline
\end{tabular}

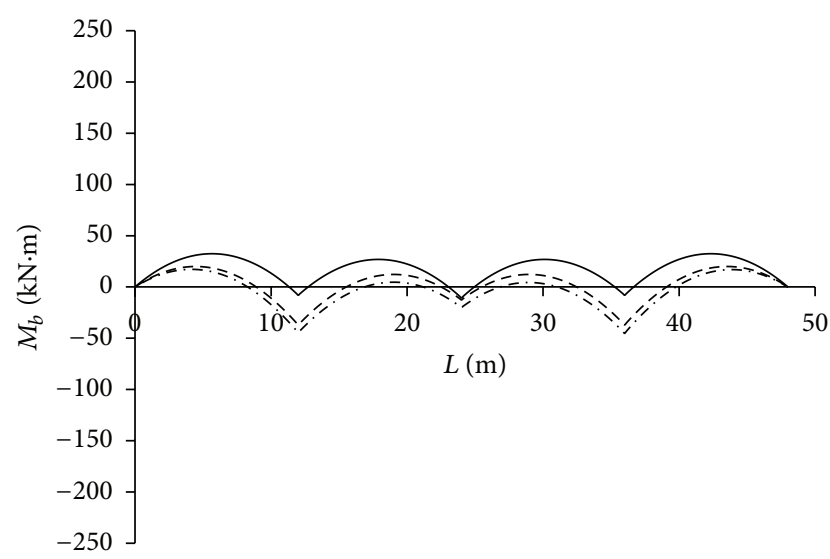

$$
\begin{aligned}
& \text { — Noncontrol results } \\
& -\cdot-\text { LDC results } \\
& --- \text { NDC results }
\end{aligned}
$$

Figure 12: Moment state of the beam under load Case 3.

carried out to verify the feasibility and accuracy of the static control algorithm. With the example study completed, some conclusions are summarized as follows.

(1) As a semirigid structure, the BSS has certain nonlinear behaviour. Comparisons between results from the NDC and LDC show that the computationalcontrolled effect of the NDC is somewhat more significant than LDC.

(2) When the structure is under downward loads, the working status of the adaptive BSS has been significantly improved after control, and the adaptive BSS has much stronger capability than the noncontrolled one. To unsymmetrical distributed loads, wider adjustment range of the active struts is required.
Obviously, the displacement and moment states of the beam become well distributed after control.

(3) The upward loads make the cable slack, and the capability of the structure is mainly subject to the allowable minimal tension of the cable. The adjustment effect of the active struts to the upward loads is not obvious.

\section{Acknowledgments}

The work described in this paper was financially supported by the National Key Technology R\&D Program (2012BAJ07B03), the National Science Foundation of China (Grant no. 51178415), and Qianjiang Scholar Foundation of Zhejiang Province (2013R10038).

\section{References}

[1] M. Saitoh, "Hybrid form-resistance structure," in Shells, Membranes, and Space Frames: Proceedings of the IASS Symposium on Membrane Structures and Space Frames, Osaka, Japan, Butterworth-Heinemann Limited, 1986.

[2] M. Saitoh, A. Okada, K. Maejima, and T. Gohda, "Study on mechanical characteristics of a light-weight complex structure composed of a membrane and a beam string structure," in Proceedings of the IASS-ASCE International Symposium on Spatial, Lattice and Tension Structures, pp. 632-641, April 1994.

[3] Y. Wang and K. H. Law, "Wireless sensor networks in smart structural technologies," in Recent Advances in Wireless Communications and Networks, J.-C. Lin, Ed., InTech, 2011.

[4] Z.-D. Xu, Y.-P. Shen, and Y.-Q. Guo, "Semi-active control of structures incorporated with magnetorheological dampers using neutral networks," Smart Materials and Structures, vol. 12, no. 1, pp. 80-87, 2003.

[5] Z.-D. Xu, "Earthquake mitigation study on viscoelastic dampers for reinforced concrete structures," Journal of Vibration and Control, vol. 13, no. 1, pp. 29-43, 2007.

[6] Z.-D. Xu, Q. Tu, and Y.-F. Guo, "Experimental study on vertical performance of multi-dimensional earthquake isolation and 
mitigation devices for long-span reticulated structures," Journal of Vibration and Control, vol. 18, no. 13, pp. 1971-1985, 2012.

[7] H. Li, H. Qian, and G. Song, "Experimental and analytical investigation on innovative hybrid shape memory alloys dampers for structural control," in Active and Passive Smart Structures and Integrated Systems 2008, vol. 6928 of Proceedings of SPIE, March 2008.

[8] G. Song, B. Kelly, B. N. Agrawal, P. C. Lam, and T. S. Srivatsan, "Application of shape memory alloy wire actuator for precision position control of a composite beam," Journal of Materials Engineering and Performance, vol. 9, no. 3, pp. 330-333, 2000.

[9] L. Li, G. Song, and J. Ou, "Hybrid active mass damper (AMD) vibration suppression of nonlinear high-rise structure using fuzzy logic control algorithm under earthquake excitations," Structural Control and Health Monitoring, vol. 18, no. 6, pp. 698709, 2011.

[10] V. Sethi and G. Song, "Multimodal vibration control of a flexible structure using piezoceramic sensor and actuator," Journal of Intelligent Material Systems and Structures, vol. 19, no. 5, pp. 573582, 2008.

[11] G. Li and L. A. Fahnestock, "Seismic response of single-degreeof-freedom systems representing low-ductility steel concentrically braced frames with reserve capacity," Journal of Structural Engineering, vol. 139, no. 2, pp. 199-211, 2013.

[12] G. Li, L. A. Fahnestock, and H.-N. Li, "Simulation of steel brace hysteretic response using the force analogy method," Journal of Structural Engineering, vol. 139, no. 4, pp. 526-536, 2013.

[13] T. Noack, J. Ruth, and U. Müller, "Adaptive hybrid structures," in Proceedings of the International Conference on Adaptable Building Structures, Eindhoven, The Netherlands, 2006.

[14] W. Sobek and P. Teuffel, "Adaptive systems in architecture and structural engineering," in Smart Structures and Materials 2001: Smart Systems for Bridges, Structures, and Highways, vol. 4330 of Proceedings of SPIE, pp. 36-45, March 2001.

[15] J. Du, H. Bao, D. Yang, Y. Wang, and C. Cui, "Initial equilibrium configuration determination and shape adjustment of cable network structures," Mechanics Based Design of Structures and Machines, vol. 40, no. 3, pp. 277-291, 2012.

[16] J. Sobieszczanski-Sobieski, J.-F. Barthelemy, and K. M. Riley, "Sensitivity of optimum solutions of problem parameters," AIAA Journal, vol. 20, no. 9, pp. 1291-1299, 1982. 


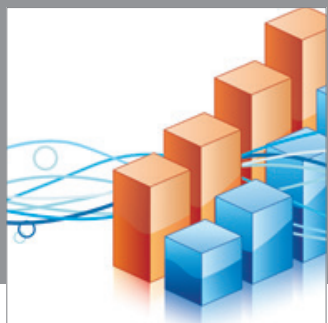

Advances in

Operations Research

mansans

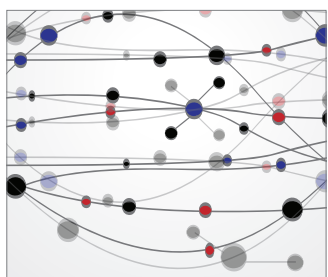

The Scientific World Journal
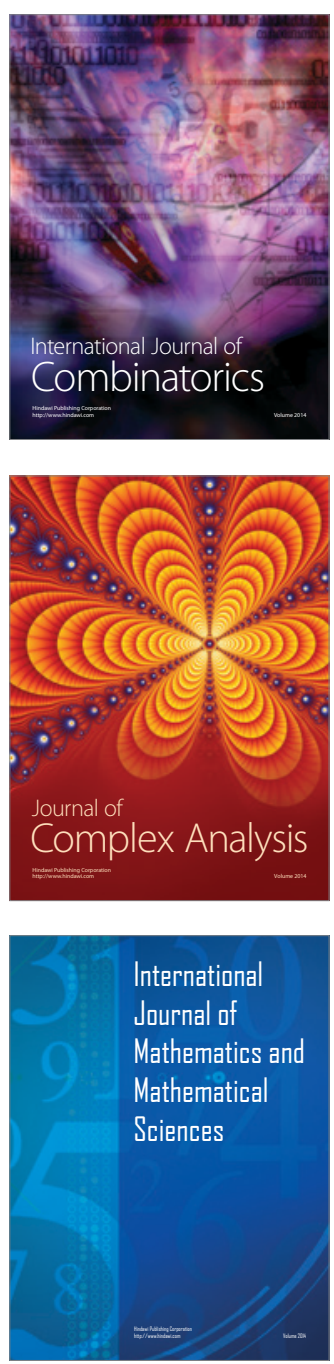
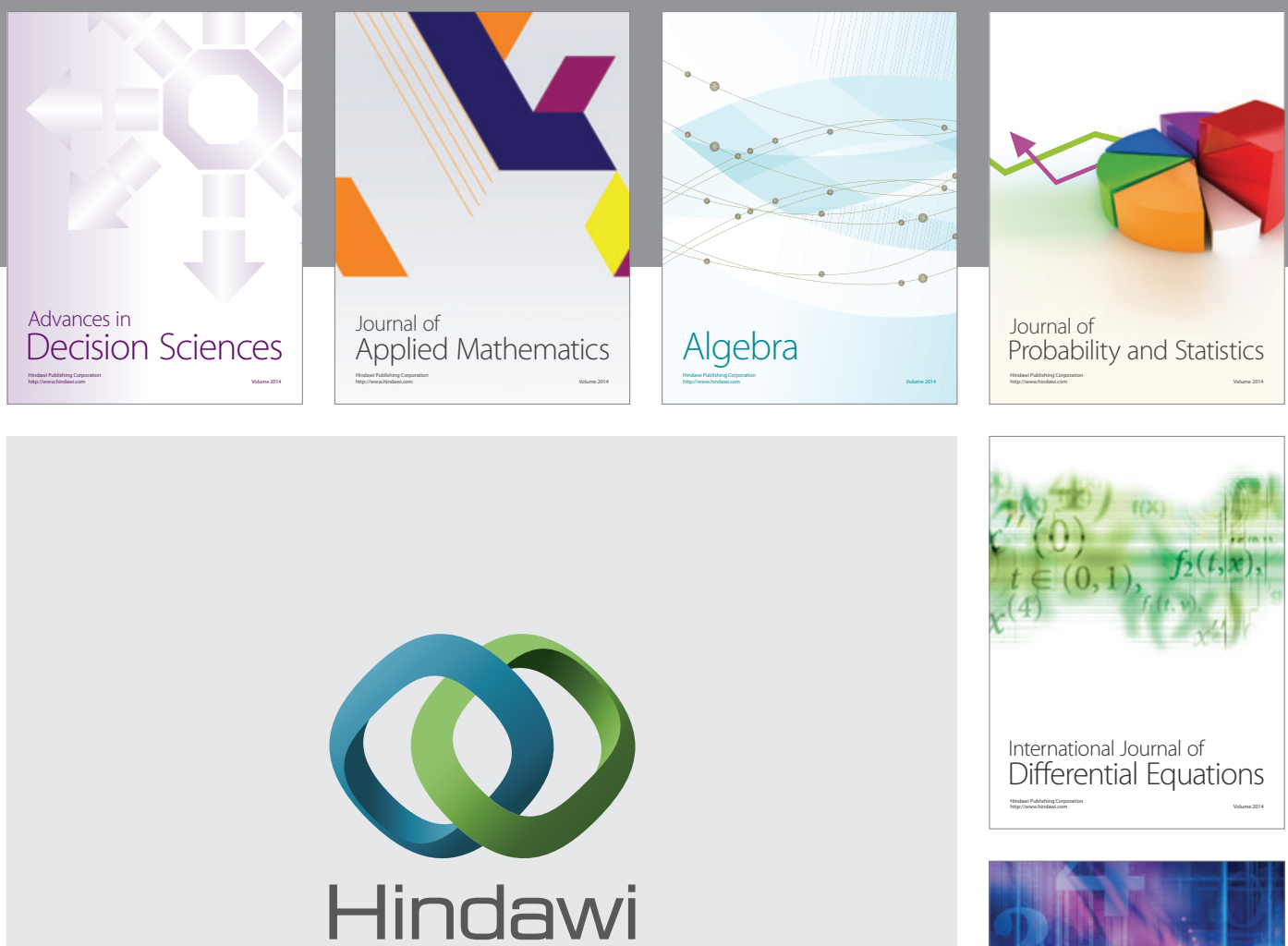

Submit your manuscripts at http://www.hindawi.com
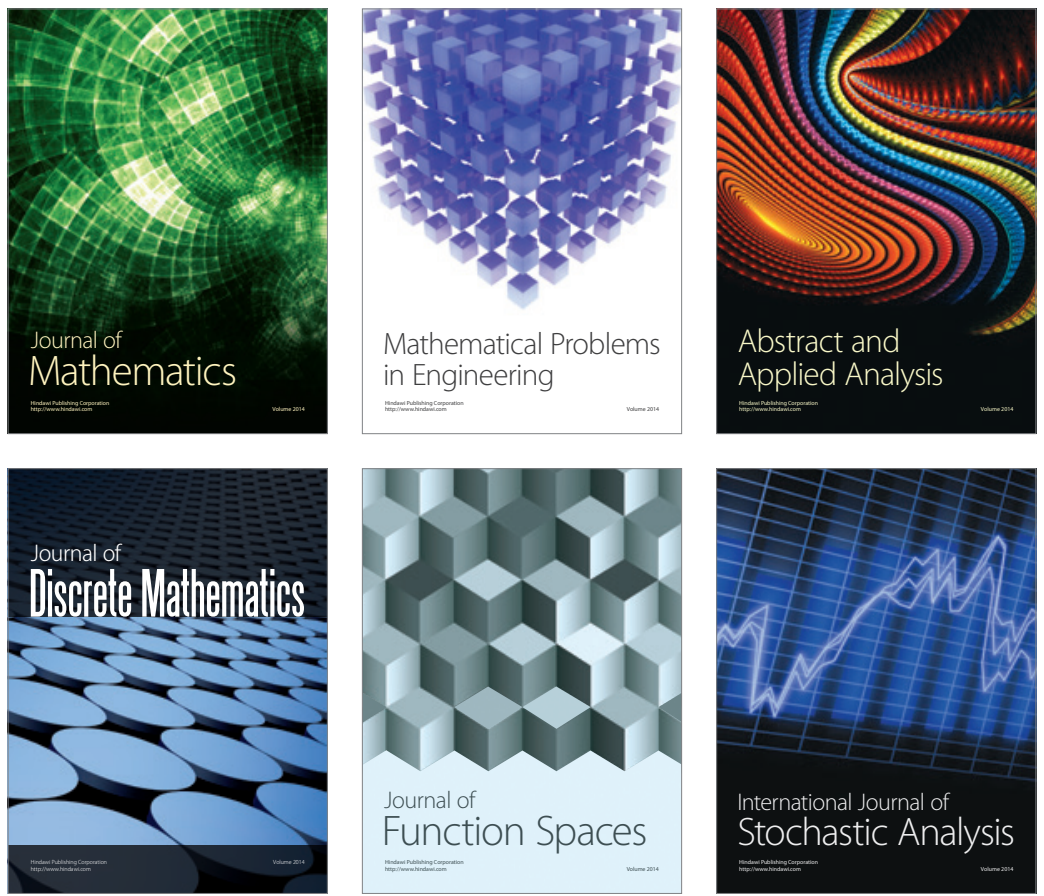

Journal of

Function Spaces

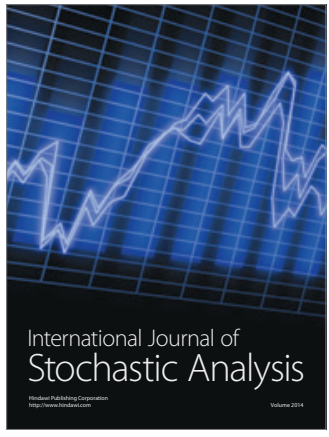

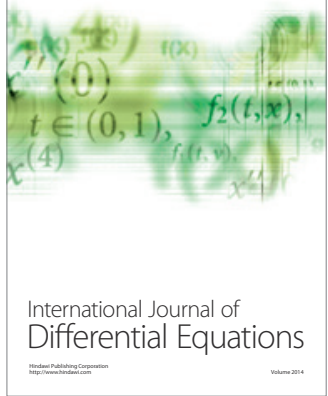
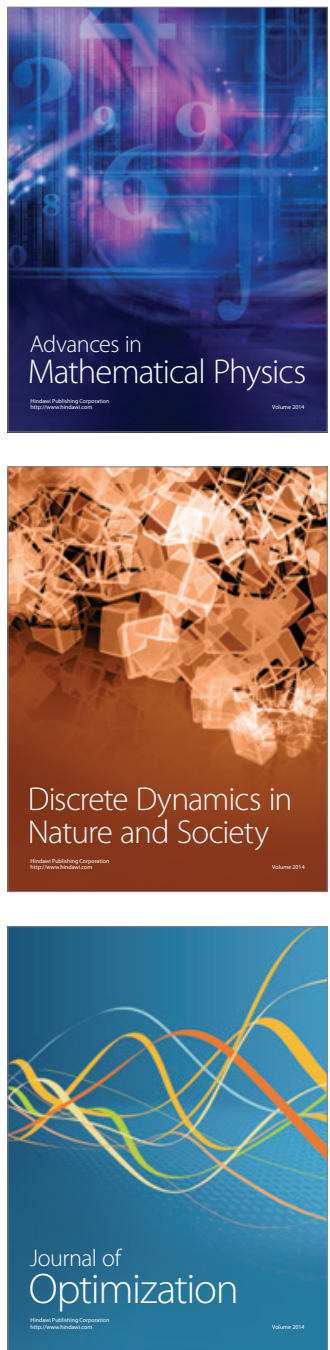